\title{
Tropical Infection Induced Hemophagocytic Lympho- Histiocytosis
}

\author{
Pannu AK* and Sharma N \\ Department of Internal Medicine, Post Graduate Institute of Medical Education and Research, Chandigarh, India
}

Received: 09 November, 2016; Accepted: 15 November, 2016; Published: 26 November, 2016

*Corresponding author: Ashok kumar Pannu, Department of Internal Medicine, Post Graduate Institute of Medical Education and Research, Chandigarh, India, Tel no: +919914291115; E-mail: gawaribacchi@gmail.com

\section{Abstract}

Tropical infections include Dengue, Malaria, Scrub Typhus, Leptospirosis, Typhoid and some other fevers, lead to high morbidity and mortality. Many of these cases have multi-organ dysfunction and require intensive care unit care. Hemophagocytic LymphoHistiocytosis (HLH), represent a severe hyper-inflammatory condition, can complicate the clinical course of tropical fevers.

Methods: Here we report the clinico-pathological features, laboratory data, treatment and outcome of 3 cases of tropical fever (2 scrub typhus and 1 dengue) complicated by HLH.

Results: All three patients satisfied the HLH-2004 diagnostic criteria. They had fever, acute respiratory distress syndrome, liver dysfunction and encephalopathy. In view of no response to empirical antibiotics and clinical instability, immunosuppressive therapy with dexamethasone was started. Following which all patients had a complete recovery.

Conclusion: HLH should be suspected in severe cases of tropical infections especially if there is no response to disease specific treatment. An early immunosuppressive therapy can do miracle.

\section{Introduction}

HLH is a rare and potentially fatal syndrome of pathologic immune dysregulation characterized by clinical signs and symptoms of extreme inflammation. Based upon the cause, HLH may be primary (familial or associated with immune deficiency syndromes) mainly occurring in pediatric age or secondary to infection, malignancy, or autoimmune condition.$^{[1,2]}$ The diagnosis of this condition is based upon the 'clinical and laboratory criteria' developed by HLH study Group of the Histiocyte Society 2004; having 5 out of 8 of the following: (1) fever, (2) splenomegaly, (3) peripheral cytopenias (affecting at least 2 of 3 cell lineages), (4) hypertriglyceridemia ( $>265 \mathrm{mg} / \mathrm{dL}$ ) and/ or hypofibrinogenemia $(<1.5 \mathrm{~g} / \mathrm{dL}),(5)$ hemophagocytosis in bone marrow, spleen, lymph nodes, or liver (6) serum ferritin $>500 \mathrm{mg} / \mathrm{L}$, (7) low or absent natural killer cell activity, (8) increased soluble CD25 concentration (a chain of soluble IL-2 receptor) $>2400 \mathrm{U} / \mathrm{ml}^{\left[{ }^{[3]}\right.}$

Infection induced HLH has been seen most frequently with viral (most commonly Ebstein-Barr virus) and numerous bacterial and parasitic infections. ${ }^{[4,5]}$
Only a few cases of Tropical Fevers (including Dengue, Scrub typhus, Malaria, Enteric fever and Leptospira) complicated by HLH have been reported in the literature. ${ }^{[6-9]}$ We report 3 cases of tropical fever presenting to the emergency department complicated by HLH.

The clinico-pathological features, laboratory data, treatment and outcome of the all 3 cases ( 2 scrub typhus and 1 dengue) are presented in (Table 1).

\section{Cases description}

\section{Case 1}

A 28 years old man presented on September 9, 2015 with high grade fever for 7 days, rapidly progressive dyspnea for 3 days and altered sensorium for 1 day. On general physical examination, GCS was E3V2M5, BP of 100/60, PR of 124/min, RR of $32 / \mathrm{min}$, temperature $38.4{ }^{\circ} \mathrm{C}$ and oxygen saturation (SpO2) was $80 \%$ on room air. He had no pallor, cyanosis, clubbing, pedal edema, jugular venous distension, lymphadenopathy, skin rashes or eschar. Systemic examination revealed bilateral diffuse crackles in chest, liver was palpable $2 \mathrm{~cm}$ below costal margin and tip of spleen was palpable. Central nervous system examination did not show signs of meningeal irritation or any focal neurological deficit and cardiovascular examination was unremarkable. Investigation showed a hemoglobin ( $\mathrm{Hb}$ ) of 10.4 $\mathrm{g} / \mathrm{dl}$; total leucocyte count (TLC) of $12 \times 10^{9} / \mathrm{l}$; platelet counts of $55 \times 10^{9} / \mathrm{l}$, creatinine level $2.5 \mathrm{mg} / \mathrm{dl}$; total bilirubin of $1.5 \mathrm{mg} /$ $\mathrm{dl}$; aspartate aminotransferase (AST), alanine aminotransferase (ALT) and alkaline phosphatase (ALP) of $198 \mathrm{IU} / \mathrm{l}, 103 \mathrm{IU} / \mathrm{l}$ and $526 \mathrm{IU} / \mathrm{l}$ respectively; serum lactate dehydrogenase (LDH) of 1362 IU/L; International Normalisation Ration (INR) of 1.08; and fibrinogen of $2.13 \mathrm{~g} / \mathrm{l}$. Arterial blood gas (ABG) analysis revealed $\mathrm{PaO2} / \mathrm{Fi} 02$ ratio of 116 and a chest $\mathrm{X}$ ray (CXR) showed diffuse bilateral lung infiltrates. Liver was $18.6 \mathrm{~cm}$ and spleen was 13.3 $\mathrm{cm}$ in size on ultrasonography.

Patient was intubated and put on mechanical ventilation with acute respiratory distress syndrome (ARDS) protocol. He was empirically started on ceftriaxone and doxycycllin. An IgM serolgy for scrub typhus was positive. Rapid kit test and peripheral smear for Malaria, serological tests for Leptospirosis (IgM antibody), 
Table 1: Clinico-pathological characteristics, laboratory data, treatment and outcome of 3 adult patients with tropical infection induced HLH (2 scrub typhus and 1 dengue)

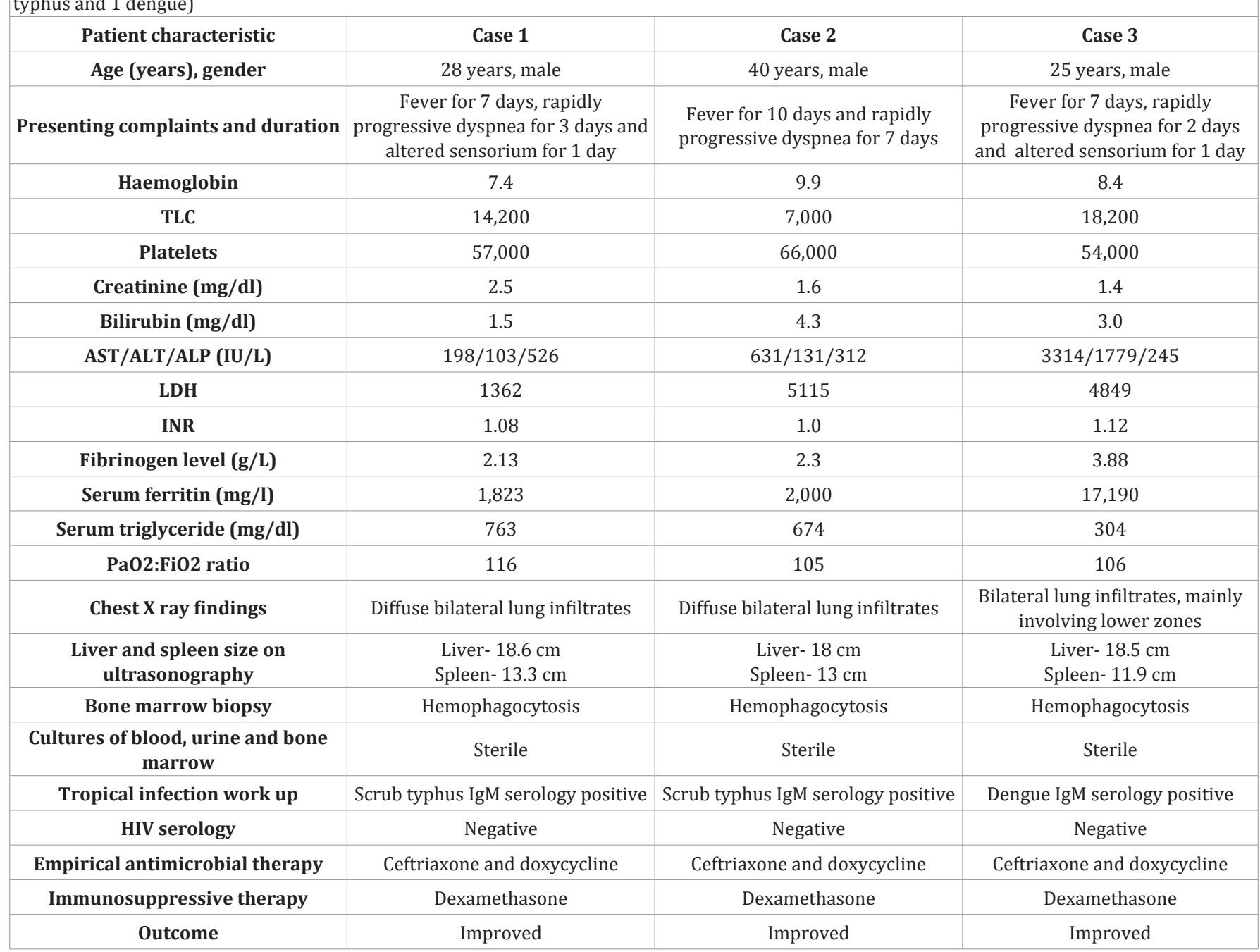

Dengue (NS1 Ag, IgM and IgG antibody), Widal, Visceral Leismaniasis (RK 39 antibody), hepatitis B surface antigen, antihepatitis C virus antibody, HIV ELISA gave negative results. Blood and urine cultures were sterile. A diagnosis of scrub typhus with multi-organ dysfunction was established. However patient did not improve, and his clinical and laboratory parameters further worsened.He had continuous high grade fever with increasing ventilator requirement. $\mathrm{PaO} 2 / \mathrm{FiO} 2$ ratio decreased to 88 with increased lung infiltrates on repeat CXR, Hb dropped to 7.4, TLC increased to $14.2 \times 10^{9} / \mathrm{l}$ and thrombocytopenia persisted $\left(57 \times 10^{9} / 1\right)$. Initially a possibility of ventilator associated pneumonia was kept and ceftriaxone was changed to imipenem after sending cultures for endotracheal aspirate, blood and urine. Despite this, patient did not improve. All cultures were sterile and serum procalcitonin was normal $(0.1 \mathrm{ng} / \mathrm{ml})$. A possibility of secondary HLH was kept in view of persisting high grade fever, cytopenias and hepatosplenomegaly. Serum ferritin was $1823 \mathrm{mg} / \mathrm{l}$, serum triglyceride was $763 \mathrm{mg} / \mathrm{dl}$ and bone marrow examination showed hemophagocytosis. Patient was started on dexamethasone on September 24. A dramatic improvement was observed, fever subsided and patient was extubated on September 27. Hb, TLC and platelet counts improved (10.4 g/ dl, $10.4 \times 10^{9} / \mathrm{l}$ and $207 \times 10^{9} / \mathrm{l}$ respectively); serum creatinine normalised ( $0.5 \mathrm{mg} / \mathrm{dl})$; and AST, ALT and ALP decreased (56, 78 and 209 respectively); serum creatinine normalised $(1.0 \mathrm{mg} / \mathrm{dl})$; and AST, ALT and ALP decreased (51, 64 and 257 respectively). Patient had made a complete recovery on a follow up visit at the medicine outpatient department 15 days after the discharge.

\section{Case 2}

A 40 years old man presented on October 25, 2015 with high grade fever for 10 days and rapidly progressive dyspnea for 7 days. On physical examination, GCS was E4V5M6, BP of 100/60, PR of $100 / \mathrm{min}$, RR of $26 / \mathrm{min}$, temperature $39{ }^{\circ} \mathrm{C}$ and oxygen saturation (Sp02) was 76\% on room air. He had pallor but no cyanosis, clubbing, pedal edema, jugular venous distension, lymphadenopathy, skin rashes or eschar. Respiratory system examination revealed bilateral diffuse crackles. Per abdomen, liver was palpable $3 \mathrm{~cm}$ below costal margin and spleen was just palpable on deep inspiration. Central nervous system and 
cardiovascular examination was normal. Investigation showed an $\mathrm{Hb}$ of $9.9 \mathrm{~g} / \mathrm{dl}$; TLC of $7 \times 10^{9} / \mathrm{l}$; platelet counts of $66 \times 10^{9} / \mathrm{l}$; creatinine level of $1.6 \mathrm{mg} / \mathrm{dl}$; total bilirubin of $4.3 \mathrm{mg} / \mathrm{dl}$, AST, ALT and ALP of $631 \mathrm{IU} / \mathrm{l}, 131 \mathrm{IU} / \mathrm{l}$ and $312 \mathrm{IU} / \mathrm{l}$ respectively; LDH of $5115 \mathrm{IU} / \mathrm{L}$; INR of 1.0; and fibrinogen of $2.3 \mathrm{~g} / \mathrm{l}$. ABG revealed PaO2/Fi02 ratio of 105 and a CXR showed diffuse bilateral lung infiltrates. Liver was $18 \mathrm{~cm}$ and spleen was $13 \mathrm{~cm}$ in size on ultrasonography.

Patient was started on ceftriaxone, doxycycllin and high flow oxygen supplementation. An IgM serology for scrub typhus was positive. Rapid kit test and peripheral smear for Malaria, serological tests for Leptospirosis (IgM antibody), Dengue (NS1 Ag, IgM and IgG antibody), Widal, Visceral Leishmaniasis (RK 39 antibody), viral hepatitis (hepatitis A virus IgM, hepatitis E virus IgM, hepatitis B surface antigen, anti-hepatitis C virus antibody), HIV ELISA gave negative results. Blood and urine cultures were sterile. Serum ferritin was $2000 \mathrm{mg} / \mathrm{l}$, serum triglyceride was 674 $\mathrm{mg} / \mathrm{dl}$ and bone marrow examination showed hemophagocytosis.

A diagnosis of scrub typhus with HLH and multi-system involvement was made. Initially patient was managed with antibiotics alone. However during hospital stay, he developed altered mental status, which was managed with a short course (3 days) of dexamethasone. Investigation showed a Hb improved (10.9 g/dl, $7.4 \times 10^{9} / \mathrm{l}$ and $232 \times 10^{9} / \mathrm{l}$ respectively); serum creatinine normalised $(1.0 \mathrm{mg} / \mathrm{dl})$; and AST, ALT and ALP decreased (51, 64 and 257 respectively).

Patient had made a complete recovery on a follow up visit at the medicine outpatient department 10 days after the discharge.

\section{Case 3}

A 25 years old man presented on November 19, 2015 with high grade fever for 7 days, rapidly progressive dyspnea for 2 days and altered sensorium for 1 day. On physical examination, patient was agitated with GCS of E3V4M5, BP of 127/70, PR of $128 / \mathrm{min}$, RR of $32 / \mathrm{min}$, temperature $38.8^{\circ} \mathrm{C}$ and SpO2 was $96 \%$ on oxygen supplementation with Fio2 0.5 and flow $12 \mathrm{l} / \mathrm{min}$. He had no pallor, cyanosis, clubbing, pedal edema, jugular venous distension, lymphadenopathy, skin rashes or eschar. Respiratory system examination revealed bilateral diffuse crackles, predominantly on basal regions. Per abdomen, liver was palpable $2 \mathrm{~cm}$ below costal margin and spleen was not palpable. Central nervous system examination did not show signs of meningeal irritation or any focal neurological deficit and cardiovascular examination was unremarkable. Investigation showed a $\mathrm{Hb}$ of $12.9 \mathrm{~g} / \mathrm{dl}$; TLC of $18.2 \times 10^{9} / \mathrm{l}$; platelet counts of $54 \times 10^{9} / \mathrm{l}$; creatinine level of $1.4 \mathrm{mg} / \mathrm{dl}$; total bilirubin of $3.0 \mathrm{mg} / \mathrm{dl}$; AST, ALT and ALP of $3314 \mathrm{IU} / \mathrm{l}, 1779 \mathrm{IU} / \mathrm{l}$ and $245 \mathrm{IU} / \mathrm{l}$ respectively; LDH of $4849 \mathrm{IU} / \mathrm{L}$; INR of 1.12; and fibrinogen of $3.88 \mathrm{~g} / \mathrm{l}$. ABG revealed $\mathrm{PaO} 2 / \mathrm{FiO} 2$ ratio of 106 and a CXR showed bilateral lung infiltrates mainly involving lower zones. Liver was $18.5 \mathrm{~cm}$ and spleen was $11.9 \mathrm{~cm}$ in size on ultrasonography.

Patient was intubated and put on mechanical ventilation with ARDS protocol. He was started on ceftriaxone and doxycycllin.
An IgM serology for Dengue was positive. Rapid kit test and peripheral smear for Malaria, serological tests for Leptospirosis (IgM antibody), Scrub Typhus (IgM antibody), Widal, Viral Hepatitis (hepatitis A virus IgM, hepatitis E virus IgM, hepatitis B surface antigen, anti-hepatitis C virus antibody), HIV ELISA gave negative results. Blood and urine cultures were sterile. A diagnosis of severe Dengue with multi-organ involvement was made. However patient did not respond, and he had continuous high grade fever with persisting altered sensorium and ventilatory requirement.

Hb dropped to 8.4. A possibility of secondary HLH was kept in view of persisting fever and development of bicytopenia. Serum ferritin was $17190 \mathrm{mg} / \mathrm{l}$, serum triglyceride was $304 \mathrm{mg}$ / $\mathrm{dl}$ and bone marrow examination showed hemophagocytosis. Patient was started on dexamethasone followed by improvement of clinical and laboratory parameters. Patient had made a complete recovery on a follow up visit at the medicine outpatient department 7 days after the discharge.

\section{Discussion}

Tropical fevers are defined as infections that are prevalent in, or unique to tropical and subtropical regions of the world. Some of these occur throughout the year and some especially in rainy and post-rainy season. These fevers mainly include infectious diseases like Leptospirosis, Enteric fever, Malaria, Dengue and Scrub typhus (can be remembered as mnemonic LEMDS). Most of these tropical infections have overlapping clinical features, multi-system involvement often requiring intensive care unit care and advance life support measures like vasopressor support, mechanical ventilation, hemostatic resuscitation and renal replacement therapy and have an increased morbidity and mortility. ${ }^{[10]}$

Infections are a major trigger for adult HLH, an appropriate targeted antimicrobial therapy is a cornerstone of management. Patients who are clinically stable and respond to treatment of the underlying infection may be able to avoid HLH-specific treatment. However, for severely ill patients, initiation of HLHspecific therapy should not be delayed while awaiting resolution of an underlying infection. In general, treatment entails the suppression of an overactive immune system.

The current treatment protocol of adult or acquired HLH is based on the pediatric HLH-94/-2004 protocol. ${ }^{[1,2]}$ Not all patients with acquired HLH need to be started on the full protocol. Immunosuppressive agents (including corticosteroids, intravenous immunoglobulin, rituximab, cyclosporine alone or in combination) are mainstay of treatment for most of the acquired HLH and infection triggered HLH responds well with corticosteroid alone. However if the disease worsens or does not respond rapidly, full therapy must be initiated quickly. ${ }^{[11,12]}$

HLH is a life threatening condition and is often missed in adults. It is diagnosed with an immediate need for treatment due to imminent respiratory, hepatic, renal, or hematopoietic failure, without a definitive diagnosis as to whether HLH has a hereditary background (degranulation assay and/or mutation analysis reports pending). Control of overt inflammation is of utmost importance..$^{[2]}$ 
It should be suspected in patients with tropical fevers, especially in the presence of multi-organ failure, persistent high fever and variable cytopenia. Respiratory distress is frequently present and respiratory insufficiency represents a negative prognostic sign and may need assisted ventilation.Early diagnosis and early effective therapy could reduce the mortality.

\section{References}

1. Campo M, Berliner N. Hemophagocytic Lymphohistiocytosis in Adults. Hematol Oncol Clin North Am. 2015;29(5):915-925. doi: 10.1016/j.hoc.2015.06.009.

2. Nikiforow S, Berliner N. The unique aspects of presentation and diagnosis of hemophagocytic lymphohistiocytosis in adults. Hematology Am Soc Hematol Educ Program. 2015;2015:183-189. doi: 10.1182/asheducation-2015.1.183.

3. Henter JI, Horne A, Arico M, Egeler RM, Filipovich AH, Imashuku S, et al. HLH-2004: diagnostic and therapeutic guidelines for hemophagocytic lymphohistiocytosis. Pediatr Blood Cancer. 2007;48:124-131. doi:10.1002/pbc.21039.

4. Riviere S, Galicier L, Coppo P, Marzac C, Aumont C, Lambotte O, et al Reactive hemophagocytic syndrome in adults: a retrospective analysis of 162 patients. Am J Med 2014;127:1118-1125. doi: 10.1016/j. amjmed.2014.04.034.

5. Tseng YT, Sheng WH, Lin BH, Lin CW, Wang JT, Chen YC, et al. Causes, clinical symptoms, and outcomes of infectious diseases associated with hemophagocytic lymphohistiocytosis in Taiwanese adults. J Microbiol Immunol Infect 2011;44(3):191-197. doi: 10.1016/j. jmii.2011.01.027.

6. Rajagopala S, Singh N, Agarwal R, Gupta D, Das R. Severe hemophagocytic lymphohistiocytosis in adults-experience from an intensive care unit from North India. Indian J Crit Care Med. 2012;16(4):198-203. doi: 10.4103/0972-5229.106501.

7. Kodan P, Chakrapani M, Shetty M, Pavan R, Bhat P. Hemophagocytic lymphohistiocytosis secondary to infections: A tropical experience!. J Postgrad Med. 2015;61(2):112-115. doi: 10.4103/00223859.150904.

8. Ellis EM, Sharp TM, Pérez-Padilla J, González L, Poole-Smith BK, Lebo E, et al. Incidence and Risk Factors for Developing Dengue-Associated Hemophagocytic Lymphohistiocytosis in Puerto Rico, 2008 - 2013. PLoS Negl Trop Dis. 2016;10(8):e0004939. doi: 10.1371/journal. pntd.0004939.

9. Basheer A, Padhi S, Boopathy V, Mallick S, Nair S, Varghese RG, et al. Hemophagocytic Lymphohistiocytosis: an Unusual Complication of Orientia tsutsugamushi Disease (Scrub Typhus). Mediterr J Hematol Infect Dis. 2015;7(1): e2015008. doi: 10.4084/MJHID.2015.008.

10. Singhi S, Chaudhary D, Varghese GM, Bhalla A, Karthi N, Kalantri S, et al. Tropical fevers: Management guidelines. Indian J Crit Care Med. 2014;18(2):62-69. doi: 10.4103/0972-5229.126074.

11. Jordan MB, Allen CE, Weitzman S, Filipovich AH, McClain. How I treat hemophagocytic lymphohistiocytosis. Blood. 2011;118(15):40414052. doi: 10.1182/blood-2011-03-278127.

12. Rosee PL. Treatment of hemophagocytic lymphohistiocytosis in adults. Hematology. Am Soc Hematol Educ Program. 2015;2015:190196. doi: 10.1182/asheducation-2015.1.190. 